\title{
Screening a state middle school for asthma using the free running asthma screening test
}

\author{
D Williams, J Bruton, I Wilson
}

\begin{abstract}
The free running asthma screening test (FRAST) was used to screen children in a state middle school during a normal physical education lesson. The test was conducted by the teachers with a general practitioner available via a radiopager. Of the 249 children attending the school, aged 8-12 years, $237(95 \%)$ were tested. Twenty two $(9 \%)$ children were known to have asthma, of whom 18 were tested. Thirty one children had a significant decrease $(>15 \%)$ in their peak expiratory flow rate (PEFR) after exercise. Six of these children were known to have asthma, indicating that their asthma treatment may be suboptimal. A further six children assessed clinically had false positive results.
\end{abstract}

The 31 children with significant decreases in their PEFR were matched for age and sex with a control group of 30 children who were considered to have a normal result. Of the control group, one child had clinical asthma. In total, $19(8 \%)$ new cases of asthma were identified, giving an overall prevalence of asthma in the school of $16 \%$.

These results indicate that it is feasible to screen schools for asthma using the FRAST. Children with undiagnosed asthma can be identified and the control of children with known asthma monitored.

(Arch Dis Child 1993; 69: 667-669)

There has been far greater awareness of asthma by the general public and doctors over the past 20 years. $^{12}$ In a 1992 study, however, only $49 \%$ of wheezy children had been correctly diagnosed as having asthma, ${ }^{3}$ showing that asthma is still substantially underdiagnosed. Fifteen per cent of wheezy children never present to their doctor at all. ${ }^{4}$ Also, many children with known asthma are inadequately treated ${ }^{5-7}$ in relation to current guidelines. ${ }^{8}$ Against this background a screening programme for asthma to identify undiagnosed cases and to monitor the control of children with known asthma appears to be worthwhile.

A method of using the free running asthma screening test (FRAST) ${ }^{9}$ has been developed to enable most schoolchildren to be screened for asthma by their own teachers, under general practitioner supervision, in a normal physical education class.

To gauge the sensitivity and specificity of using the FRAST in this context, children with positive results were matched with a control group with negative results. All the children were then reviewed blindly. They were assessed clinically and these results were then compared with the FRAST results.

\section{Subjects and methods}

All the children attending a state middle school aged 8-12 years from mixed socioeconomic backgrounds were invited to be tested using the FRAST over a two week period during the pollen season (May-June). The school was approached and the consent of the head teacher and governors was obtained. A letter was sent to all parents seeking their consent. The nature of the test was explained and they were invited to ask questions or withdraw their child from the test if they so wished.

The children measured their height during a maths lesson and this was checked by the teaching staff. The height was recorded along with the predicted peak expiratory flow rate (PEFR) that was read from a table of height against expected PEFR compiled by JB and DW. The test was performed during a normal physical education lesson to cause minimum disruption to school activities. All drugs were taken as usual. Any child exempted from physical education, along with the reason for exemption, was noted.

During the lesson the children had their preexercise PEFR measured using a mini-Wright peak flow meter. This was recorded as the best of two measurements and was compared with their expected PEFR to provide a check of technique. The children then performed sustained maximum running for five minutes. ${ }^{9} 10$ The level and continuity was supervised by teachers experienced in physical education (numbering one to two for each class). A rest period of five minutes followed. Between five and 10 minutes after exercise the PEFR was recorded as the best of two measurements. A doctor was available via a radiopager throughout the test period.

Children who showed a decrease in PEFR greater than or equal to $15 \%$ of the pre-exercise value ${ }^{9-11}$ were given a letter stating that they should be reviewed by a doctor (JB or DW) two weeks later. A control group, matched for age and sex with no decrease in PEFR after exercise was also sent letters. The controls were selected by choosing children with normal results from the same class and of the same sex as children with significant decreases in PEFR after exercise. The children were then reviewed blind to both parent and doctor. Clinical history was recorded, enquiring into symptoms of wheezing, cough, or dyspnoea, especially in relation to exercise, 
upper respiratory tract infections, or time of day. Relevant family history was collected, the child's respiratory system was fully examined, and then the test results were revealed. If the clinical assessment was negative but the test was positive, the test was repeated. The test was also repeated if the initial test was negative but the history was positive. The exercise on this occasion comprised stepping on and off a box at maximum speed for five minutes with five minutes' rest and again, the best of two PEFR measurements between five and 10 minutes after exercise were taken. The children's radial pulse rate was taken during exercise to ensure the level of activity caused a sustained heart rate of approximately $170 .^{91112}$ If the clinical assessment or test result, or both, were positive, it was explained that the child probably had asthma or that their control may have been suboptimal, ${ }^{9}$ and further management was referred to the family doctor. A letter giving an explanation of the test was sent to the family doctor.

Subsequent to the screening procedure, the parents of the children with known asthma were contacted and the children's normal asthma treatment noted. The test results of these children were then reviewed.

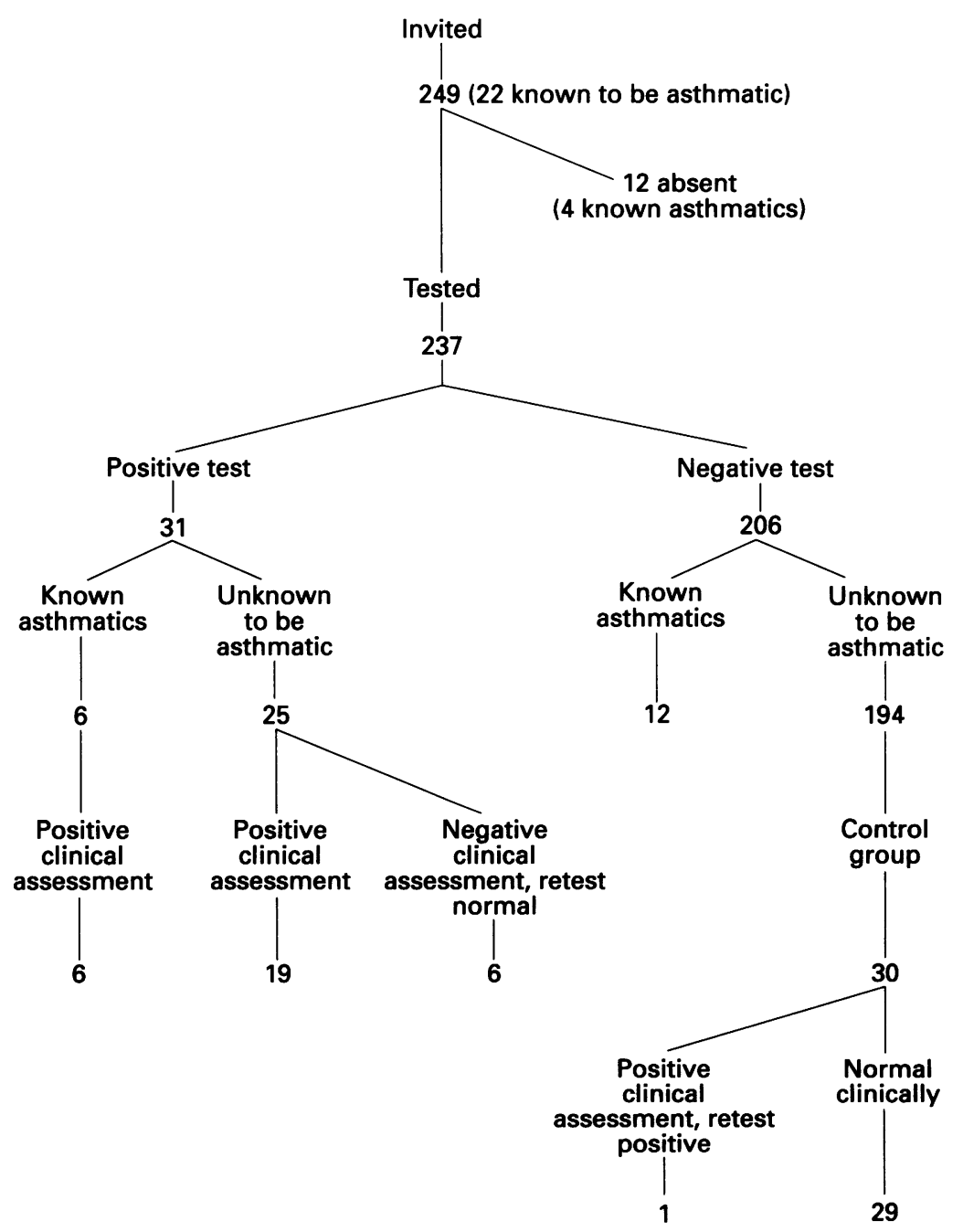

Results of free running asthma screening test.

\section{Results}

There were 249 children in the school (116 boys and 133 girls). Twenty two (9\%) children were known to have asthma. There were 12 (5\%) exemptions from the test. Two had upper respiratory tract infections, one of whom was already known to have asthma. Other reasons for exemption included injury, gastrointestinal infection, attendance at an outpatient (non-respiratory) clinic, and holidays. Of the exemptions, four were known to have asthma (33\%). Of the 237 children tested, all completed the test. Of all the children tested, $31(13 \%)$ had an initially positive test result. There were six children known to have asthma in this group. The remaining 12 children known to have asthma had negative test results (figure).

The range of abnormal decrease in PEFR was $15-56 \cdot 5 \%$ with a mean of $26 \%$. In spite of a limited choice of appointment times, all those invited for follow up attended. On recording history and physical examination, 25 children were still positive. Six were known to have asthma. Six children had a negative history and a negative retest and history. The control group had one positive result from history and retesting (figure).

Of the six children known to have asthma with a significant decrease in PEFR, three were not receiving treatment, two were receiving only agonist inhaler, and one was using a prophylactic inhaler. Of the 12 children known to have asthma without a significant decrease in PEFR, four were receiving prophylactic inhalers, seven were receiving agonist inhaler alone, and one was receiving no treatment.

The total amount of teacher time spent for each class of 20 children was 60 minutes.

\section{Discussion}

In this study there were 22 children known to have asthma and another 19 children with previously undiagnosed asthma. This gave an overall prevalence of asthma of $16 \%$ in this school. Of the 18 children known to have asthma who were tested, six had a positive FRAST result, indicating that their asthma treatment may have been suboptimal. ${ }^{9}$

There are a number of differences between this study and that of Tsanakas et al. ${ }^{9}$ The temperature and humidity of the school gymnasium was not carefully controlled. On a practical level it would not be possible to have all school gymnasiums at the same temperature and humidity on the day of testing. The cooler the temperature the more likely it is that exercise induced asthma will be provoked. ${ }^{13}$ The trained medical staff were not available on site, but were 'on call'. The exercise the children performed was no more than would be expected in a normal physical education class. Requiring a doctor, which in this context would be a general practitioner, to be present as opposed to available during testing would limit the use of FRAST as a screening procedure. Tsanakas et al ${ }^{9}$ reported that the PEFR measurements taken five and 10 minutes after exercise were the most useful. With classes of 
20 children it was difficult to carry out all PEFR measurements at five and then at 10 minutes. Hence the best of two PEFR measurements between five and 10 minutes was selected. The retest exercise, providing the heart rate is adequately increased, 1112 should be as potent a stimulator of asthma as running. ${ }^{14}$ This test was used for convenience in the surgery.

Using FRAST as a screening procedure is based on about $84 \%$ of children known to have asthma having exercise induced bronchospasm. ${ }^{11}$ Exercise may not provoke asthma in the remaining $16 \%$ of children, or exercise may not provoke asthma on the day of testing, as is confirmed by the identification of one control with a negative test result who gave a positive clinical assessment and positive retest exercise result. Reviewing the children with positive test results showed that detecting PEFR decreases of $15 \%$ or more after exercise identified children with a positive clinical assessment of asthma. Having a control group eliminated bias in this assessment and gave an indication of the sensitivity of the test by identifying false negative results. Of the 31 initially abnormal results, six (19\%) were false positives.

Another way of screening for asthma is using questionnaires. There are a number of problems with questionnaires. The response rate, even with reminders, is unlikely to exceed $80-85 \%,{ }^{315}$ and may be as low as $55 \%$ in Asian families. ${ }^{16}$ A variety of influences mediate replies given to questions. ${ }^{17}$ For example, in Tuscon, USA only women screened positive for asthma. ${ }^{18}$ In many languages it is difficult to find a translation for the word 'wheeze'. ${ }^{17}$ The optimum way of screening for asthma may be a questionnaire completed by parents and a FRAST conducted by teachers on a yearly basis.
It is concluded that this method for using the FRAST is feasible in a school environment. Previously undiagnosed children with asthma could be identified and the control of children with known asthma could be monitored.

1 Hill R, Williams J, Tattersfield A, Britton J. Change in use of asthma as a diagnostic label for wheezing illness in schoolchildren. BMf 1989; 299: 898 .

2 Strachan DP, Anderson HR. Trends in hospital admission rates for asthma in children. BMF 1992; 304: 819-20.

3 Ninan T, Russell G. Respiratory symptoms and atopy in Aberdeen school children: evidence from two surveys 25 years apart. $B M \mathcal{F}$ 1992; 304: 873-5.

4 Anderson HR, Bailey PA, Cooper JS, Palmer JC, West S. Medical care of asthma and wheezing illness in children: a community survey. $\mathcal{F}$ Epidemiol Community Health 1983; 37: $180-6$.

5 Robertson CF, Rubinfeld AR, Bowes G. Paediatric asthma deaths in Victoria: the mild are at risk. Pediatr Pulmonol 1992; 13: 95-100.

6 Sears MR, Rea HH, Rothwell RPG, et al. Asthma mortality: comparison between New Zealand and England. $B M \mathcal{Y}$ 1986; 293: 1342-5.

7 British Thoracic Association. Death from asthma in two regions of England. BMF 1982; 285: 1251-5.

8 Guidelines on the management of asthma. Thorax 1993; 48 (suppl): S1-24.

9 Tsanakas JN, Milner RDG, Bannister OM, Boon AW. Free running asthma screening test. Arch Dis Child 1988; 63:

10 Bierman W, Kawabori I, Pierson W. Incidence of exercise induced asthma in children. Pediatrics 1975; 56 (suppl): 847-50.

11 Godfrey S. Childhood asthma. In: Clark TJH, Godfrey S, eds. Asthma. London: Chapman and Hall, 1992: 97-8.

12 Tsanakas JN, Bannister OM, Boon AW, Milner RDG. The 'sport-tester': a device for monitoring the free running test. Arch Dis Child 1986; 61: 912-4.

$13 \mathrm{McF}$ adden ER. Exercise-induced asthma. Am f Med 1980; 68: 471-2.

14 Bundgaard A, Ingemann-Hansen $\Upsilon$, Schmidt A, HalkjaerKristensen J. Exercise induced asthma after walking, running and cycling. Scand $\mathcal{f}$ Clin Lab Invest 1982; 42, runnin

15 Nocon A. Social and emotional impact of childhood asthma. Arch Dis Child 1991; 66: 458-60.

16 Hill RA, Standen PJ, Tattersfield AE. Asthma, wheezing, and school absence in primary schools. Arch Dis Child 1989; 64: 246-51.

17 Dodge R, Burrows B. The prevalence and incidence of asthma and asthma like symptoms in a general population sample. Am Rev Respir Dis 1980; 122: 561-75.

18 Burney P, Chinn S. Developing a new questionnaire for measuring the prevalence and distribution of asthma. Chest 1987; 91 (suppl): 795-835. 